\title{
DA ESPECIFICIDADE DO ESTILO RETÓRICO SEGUNDO ARISTÓTELES
}

\author{
Maria de Fátima Simões Francisco
}

\begin{abstract}
RESUMO: In this paper we intend to examine some of the suggestions regarding the style provided by Aristotle in his Rhetoric, chapters III, 2-12, in order to enable, on the one hand, the understanding of the specificity of such a style in Aristotle's conception and, on the other hand, analyze in what way the characteristics inherent to the rhetoric style are linked to the persuasive function of such speech.
\end{abstract}

PALAVRAS-CHAVE: estilo retórico, persuasão, discurso ordinário, poesia, desfamiliarização, metáfora.

O livro III da Retórica de Aristóteles é dedicado ao estudo de duas questões: o estilo (lexis) e a disposição (taxis). Sobre o estilo, definido enquanto o como se diz em contraposição ao o que se diz, o conteúdo, o autor nos fala que, embora possa não ser de importância em algumas formas de discurso, dentre as quais o da ciência, assume papel central na retórica. Nesta arte se, por um lado, o orador deve cuidar para que os argumentos tornem sua posição convincente, não deve, por outro lado, de modo algum descuidar do modo pelo qual os apresenta ao ouvinte, pois isso será decisivo para fazer persuasivo seu discurso. $\mathrm{O}$ estilo pode contribuir no mais alto grau para o caráter persuasivo do discurso, competindo a esse respeito, por assim dizer, em igualdade com seu conteúdo.

É nossa intenção examinar aqui algumas das sugestões para o estilo retórico fornecidas nos capítulos III,2-12 da Retórica, a fim de, por um lado, melhor entender a especificidade desse estilo na concepção de Aristóteles e, por outro lado, perceber de que maneira essas características próprias do estilo na retórica estão articuladas à função persuasiva desse discurso.

O primeiro ponto a atrair nossa atenção nesses capítulos é o fato de o perfil próprio do estilo do discurso retórico ser delineado por referência aos estilos de dois outros discursos, quais sejam, a poesia e o discurso ordinário ${ }^{1}$ - em relação a cada um dos quais se marcarão aproximações e distanciamentos. Note-se que o discurso científico, parâmetro fundamental de comparação no capítulo III, 1, sai de cena nesse momento, pois se trata agora de encontrar formas discursivas que demonstrem, como o discurso retórico, preocupação significativa com o estilo. Deparamos ao longo desses capítulos com menções contínuas à poesia e à linguagem do homem comum, que revestem desse modo o papel de balizas situadas em extremos opostos, a meia distância das quais se encontrará o campo próprio do estilo retórico.

Muitas são as semelhanças do discurso retórico com o discurso ordinário. Uma das principais concerne ao objeto de cada um desses dois discursos, qual seja, pessoas e temas comuns. Assemelhando-se entre si nesse ponto, ambos se distinguem, por sua vez, da poesia, em que os caracteres e assuntos são antes fora do comum. ${ }^{2}$ A trivialidade da matéria do discurso retórico determinará por si grande parte da escolha do vocabulário pelo orador: aquele não deve ser demasiado baixo, nem demasiado elevado, ou seja, estar abaixo

\footnotetext{
Maria de Fátima Simões Francisco é professora da Faculdade de Filosofia Letras e Ciências Humanas da USP

${ }^{1}$ Diferentes termos são utilizados por Aristóteles para referir o discurso ordinário: dialektos, 1404a33 e 1404b24; lektikos, 1408b33; lexis ton pollon, $1408 \mathrm{~b} 34$.

${ }^{2}$ V. 1404b13-16. A poesia é distinguida nessa passagem do discurso em prosa de um modo geral, que inclui nesse sentido tanto o discurso retórico quanto o discurso ordinário. A. Laks traduz philoi logoi por "discours nus" (1994, p. 292), isto é, os discursos desprovidos de métrica, ou a prosa em contraposição à poesia.
} 
ou acima da dignidade do assunto. Deve antes ser apropriado. Sendo semelhante ao discurso ordinário quanto ao objeto, o discurso ordinário, deverá ser também semelhante quanto ao vocabulário adotado. Alcança-se desse modo o efeito visado da limitação da elevação. Concretamente a escolha lexical privilegiará os termos de uso comum, aplicados em seu sentido principal (ta kyria) e primeiro (oikeion), evitará os termos em desuso (glotta), os termos compostos (dipla onomata) e os neologismos (pepoimomena), que sendo de uso raro acabam por conferir solenidade ao discurso. ${ }^{3}$ A limitação na elevação do vocabulário, é necessário frisar, deve ser seguida à risca pelo orador, perdendo seu discurso poder de persuasão, isto é, de angariar a adesão do ouvinte à opinião defendida ${ }^{4}$, toda vez que ultrapassar tal fronteira.

Essa exigência relativa à escolha do vocabulário vai na verdade diretamente ao encontro de uma expectativa do ouvinte do orador: aquele espera ver assuntos semelhantes aos da vida quotidiana tratados, do ponto de vista lexical, da mesma forma como se faz na linguagem da vida quotidiana. Espera, enfim, que a fala do orador seja apropriada ou verossímil, como condição para the parecerem convincentes seus argumentos. Ocorre, contudo, que deparamos aqui com um evidente paradoxo: para ser persuasivo, isto é, para ganhar a adesão do ouvinte, o orador deve falar como um cidadão comum no decorrer de seus afazeres quotidianos, pois o objeto de seu discurso é em tudo semelhante ao da vida comum. Entretanto, a fala do orador está longe de ser espontânea ou atécnica como o discurso ordinário. E nem poderia sê-lo, em razão justamente de assumir objetivos e propósitos que não se colocam ao discurso ordinário.

Vejamos como o filósofo nos apresenta tal paradoxo ao expor essa primeira exigência imposta ao estilo retórico de limitação da elevação pelo vocabulário.

É por isso que os autores, ao comporem, o devem fazer passar despercebido (lanthanein) e não mostrar claramente que falam com artificialidade (peplasmenos), mas sim com naturalidade (pephykotos) (pois este último modo resulta persuasivo (pithanon), o anterior, o oposto. Na verdade, as pessoas enchem-se de indignação como contra alguém que contra elas conspirasse, tal como perante vinhos adulterados). Era isto que se passava com a voz de Teodoro em comparação com a dos outros atores: aquela parecia, na verdade, pertencer à personagem, ao passo que as outras pareciam pertencer a outras personagens quaisquer. Passa corretamente despercebido o artifício se se compõe escolhendo-se palavras da linguagem de todos os dias: isto é o que Eurípides faz e foi ele o primeiro a mostrá-lo. $(1998,1404 \mathrm{~b} 18-24)^{5}$

Não importa que opiniões sensatas o orador defenda, se ele não as apresentar com o vocabulário adequado, vale dizer, próximo da linguagem comum, seu discurso parecerá pouco convincente, e com pouca probabilidade de ganhar a adesão do ouvinte. O público espera um discurso natural (pephykotos), ou seja, espontâneo e atécnico, e suspeitaria de qualquer indício que encontrasse de uma composição artificial, como se se estivesse tramando contra ele. Ocorre todavia que a fala do orador, por ser tão somente a atualização de uma habilidade técnica com o propósito de alcançar efeitos determinados, não pode nem deve ter nada de espontâneo. Cada detalhe deve, ao contrário, ser aí fruto de uma estratégia deliberada, fundada em conhecimento técnico. O problema encontrará sua solução no ocultar (lanthanein) que se fala por arte e não espontaneamente, o que se obtém por empréstimo ao vocabulário do discurso ordinário. Verossímil, e em conseqüência persuasivo, será o orador que se fizer esquecer enquanto orador, da mesma forma que verossímil parece o ator que como Teodoro se faz esquecer enquanto ator. Assim como Teodoro passa por seu personagem, o orador deve passar por um falante comum da cidade. Outros recursos serão úteis para fazer passar despercebido o caráter artificial do discurso retórico, Aristóteles parece pensar todavia que a adoção do léxico da linguagem comum já cumpre por si boa parte dessa tarefa de dissimulação.

Embora a semelhança de objeto entre os discursos retórico e ordinário determine uma proximidade estilística fundamental entre eles em termos da escolha de palavras, ela não poderá, entretanto, nos fazer pensar que o estilo retórico se pareça em tudo àquele da linguagem comum. Pois, sendo a fala do orador, como dissemos, chamada a desempenhar funções próprias, ausentes daquela linguagem, deve igualmente lançar mão de recursos estilísticos próprios. Apesar de o público esperar um discurso espontâneo - a

\footnotetext{
${ }^{3}$ V. 1404b2-4, 1404b26-35.

${ }^{4}$ Trata-se da persuasão de um processo específico, o da pistis, pelo qual aderimos a uma opinião que nos é apresentada, cf. De Anima 428a20-21:"A opinião (doxe) envolve crença (pistis), pois, sem acreditar (pisteuein) naquilo sobre o que temos opinião, não podemos ter uma opinião." A opinião é a própria matéria do discurso retórico, pois, não sendo imediatamente evidente, deve ser defendida, isto é, deve ser objeto de persuasão.

${ }^{5}$ Utilizamos a tradução portuguesa de M. Alexandre Júnior, Paulo F. Alberto e A. N. Pena.
} 
manifestação sincera e imediata do modo de pensar do orador ${ }^{6}$-, como condição para lhe parecer persuasivo, paradoxalmente o orador perderia toda possibilidade de ser persuasivo se se limitasse a falar espontaneamente. A consequiência de uma fala natural, como o faria alguém que não detém conhecimento da arte da oratória, seria a ausência de força expressiva e, por conseguinte, de comunicação com o público. ${ }^{7}$ Ora, a função própria do estilo será de trabalhar sobre o que se diz, sobre o conteúdo, de modo a dar a ver ao público aquilo que por si mesmo poderia não ser visto. ${ }^{8}$

A linguagem ordinária, precisamente por ser demasiado familiar, pouco pode atender às necessidades específicas do falar a um público determinado como o da assembléia e do tribunal. Diante de uma audiência inculta, numerosa e, em conseqüência, dotada de variadas dificuldades - tais como, compreensão, fixação da atenção, discernimento auditivo e visual ${ }^{9}$ - uma fala atécnica estaria, sem dúvida, pouco munida para fazer face aos obstáculos intervenientes, ou seja, para chegar a comunicar algo e persuadir. É para tentar solucionar esse tipo de dificuldade que Aristóteles adiciona a segunda exigência a ser satisfeita pelo estilo retórico: a desfamiliarização ou a exploração do estranho (to xenikon) no plano do discurso ${ }^{10}$.

$\mathrm{Na}$ verdade, as pessoas sentem perante a falantes estrangeiros e concidadãos o mesmo que com a expressão enunciativa (lexis). É necessário, portanto, produzir uma linguagem não-familiar (xenen), pois as pessoas admiram o que é afastado, e aquilo que provoca admiração é coisa agradável.(1998, 1404b9-13)

O afastamento em relação às formulações da linguagem ordinária, o rompimento da expectativa do ouvinte e o efeito surpresa, formas pelas quais se produz a desfamiliarização ou o estranhamento, conferem ao discurso retórico poder de se comunicar com seu público próprio, deficiente em vários sentidos, na medida em que tornam o que se diz expressivo e capaz de captar a atenção do ouvinte. É interessante notar que esta captação resulta, segundo a passagem que vimos de citar, da produção de uma certa espécie de prazer, o do inesperado, pois o diferente, o que foge ao ordinário, inclusive no domínio do como se diz, da expressão lingüística, é causa de prazer. Vale notar aqui que o prazer será uma das dimensões mais importantes do estilo retórico e sempre com essa função de resolver as dificuldades de acompanhamento do discurso por parte do público.

Dessa forma, ao lado de um movimento de aproximação em relação ao discurso ordinário, exigido pela semelhança de objetos, vemos um outro, oposto a ele, de afastamento, chamado por Aristóteles de desfamiliarização. Um tal efeito será buscado mediante a utilização de alguns recursos, o mais importante dos quais é justamente a metáfora. Ela será, não por acaso, definida na Poética como a "aplicação de um nome

\footnotetext{
${ }^{6}$ Uma das qualidades do caráter do orador no entender do público, segundo Aristóteles, é a virtude, isto é, a capacidade de expor com sinceridade o que pensam. V. $1378 \mathrm{a} 8$.

${ }^{7}$ Quanto à menor expressividade do discurso espontâneo diante do público da situação retórica, poderíamos melhor entendê-la a partir do comentário de R. Sennet à teoria de Diderot acerca da representação cênica: "a teoria que Diderot propõe concerne bem mais do que aos truques das artes cênicas: dirige-se à superioridade do artifício sobre a natureza, na expressão de emoções... enquanto o mundo natural puder parecer superior ao mundo do ator, estará de fato muito mais vulnerável e sujeito a acidentes. Que se pense numa mulher chorando, diz Diderot, mas que tem um detalhe desfigurado qualquer, que chama nossa atenção, desviando-nos de seus lamentos; ou, então, cujo sotaque achamos difícil de entender, e assim somos distraídos; ou, ainda, que nos apresenta sua 'deixa' num momento em que estamos despreparados para recebê-la; em todos esses casos, o mundo onde as pessoas reagem direta e espontaneamente umas para com as outras é um mundo em que a expressão é freqüentemente pervertida; quanto mais natural for a expressão entre duas pessoas, menos seguramente expressiva ela será", (1988, p. 143).

${ }^{8}$ Aristóteles justifica assim no início do livro III a função do estilo no discurso retórico: "não basta possuir o que é preciso dizer, mas torna-se também forçoso expor o assunto de forma conveniente; e isto contribui em muito para mostrar de que tipo é o discurso (to phainenai poion tina ton logon).", 1403b15-18. J.-L Labarrière apresenta de modo interessante o estilo como a "art consommé du paraître et du faire paraître" (1994, p. 248)

${ }^{9}$ São várias as passagens em que o filósofo faz referência à incultura e deficiências desta decorrentes, dentre as quais temos: 1355a26-29, 1357a2-3, 1357a11-12, 1395b1-2, 1419a18-19 e 1419b30. Quanto ao problema da incultura do público e suas importantes implicações para as regras da arte retórica, longamente tematizado pelo filósofo, não podemos nos ocupar dele nesse momento. Basta-nos apenas lembrar que, sendo os ouvintes numerosos e, por isso, postados à distância do orador, agravam-se os problemas decorrentes da incultura, de dificuldade de compreensão do conteúdo do discurso. Sendo numeroso e inculto, o público está mais sujeito a mal ouvir, mal ver e mal entender o que o orador diz, sem falar na dificuldade de fixar a atenção.

${ }^{10} \mathrm{~S}$. Halliwell aproxima, de modo a nosso ver interessante, a noção aristotélica de desfamiliarização a concepções modernas: "attention to lexis as style allows and requires something akin to the now familiar notion, coined by the Russian Formalist V. Shklovsky, of 'foreground' in the language of literary texts. Shklovsky thought of foregrounding as an effect of 'estrangement' from the normal, relatively unnoticed patterns of language. Though I shall later argue that Aristotle's conception of lexis is not in fact 'formalist', it is worth noticing that he does think in a partially similar way, taking effective lexis (in rhetoric or poetry) to involve an element of 'strange' or 'foreign' (xenikon), i.e. divergence from the norm of ordinary speech", (1993, p. 54).
} 
estranho (onomatos allotriou epiphora)" (1457b6). Podemos nos dar conta da relevância desse recurso no estilo retórico ao percebermos que é sobre ele que Aristóteles mais se detém nos capítulos III,2-12. Seria preciso notar dois pontos sobre a concepção aristotélica de metáfora retórica. Por um lado, o que é assim chamado não corresponde sempre ao que se entende hoje pelo termo, além do que o próprio filósofo denomina também com esse termo outras estruturas que a simples substituição do termo esperado por um termo estranho, conforme reza sua definição. Por outro lado, a metáfora apropriada ao discurso retórico é uma bem determinada, não se confundindo com a metáfora poética, uma vez que está condicionada à limitação da elevação e deve ser imediatamente clara para o público, condições que aquela outra nem sempre atende. A recusa das metáforas poéticas de Górgias no capítulo III,3 é justificada precisamente nesses termos.

A metáfora é, dentre os recursos estilísticos mobilizados pela retórica, um dos mais afinados e ajustados com as necessidades dessa arte. Pois, além de abrigar um componente de desfamiliarização que a torna expressiva, possibilita ainda uma instrução à exata medida das carências do público, vale dizer, fácil e rápida. Diz Aristóteles:

Que seja o seguinte o nosso pressuposto: uma aprendizagem fácil e rápida é, por natureza, agradável para todos; por seu turno, as palavras têm determinado significado, de tal forma que as mais agradáveis são todas as palavras que nos proporcionam também conhecimento. É certo que há palavras que nos são desconhecidas, embora as conheçamos no seu sentido 'apropriado'; mas é sobretudo a metáfora que provoca tal. Efetivamente, sempre que ele chama à velhice 'palha', produz ensinamento e conhecimento (mathesin kai gnosin) por meio da categoria: ambos já não estão na 'flor da idade'.(1998, 1410b9-15)

A metáfora retórica atesta com precisão o princípio apresentado logo ao início do livro III $^{11}$ segundo o qual a estrutura do estilo retórico se explica inteiramente pelo fato de estar voltada para a figura do interlocutor. Diante de um público pouco capaz de bom discernimento, a única aprendizagem possível é sem dúvida a que se dá com facilidade. ${ }^{12}$ Essa qualidade da instrução proporcionada pela metáfora está diretamente relacionada ao tempo mínimo entre a emissão pelo orador e a compreensão pelo público. Por um lado, sendo a metáfora uma fórmula breve - que enuncia uma identidade, que algo é algo ${ }^{13}$ - a compreensão emerge necessariamente muito antes do que ocorreria numa paráfrase de mesmo sentido com os termos esperados, não-metafóricos. Por outro lado, o entendimento da metáfora é imediato porque a analogia subjacente entre o termo substituído e o termo substituto é passível de ser encontrada sem dificuldades. A analogia entre a velhice e a palha, o serem ambas coisas que perderam a flor da idade, é por exemplo descoberta com facilidade. De onde restringirem-se as metáforas convenientes ao uso retórico àquelas em que essa regra subjacente é facilmente notada pelo ouvinte. Metáforas que envolvam analogias distantes ou demasiado abstratas, como as de Górgias ou muitas usadas na poesia, devem ser evitadas, pois a compreensão, se porventura chegasse, viria demasiado tarde. Podemos avaliar o quanto é importante que seja ínfimo o tempo absorvido pela compreensão através da comparação, traçada por Aristóteles, entre a metáfora e o símile: sendo mais extenso e levando maior tempo para ser compreendido, é por isso mesmo menos instrutivo e menos apreciado pelo público que a metáfora. ${ }^{14}$

Em contrapartida, esse tempo não pode tão pouco ser igual a zero, como ocorreria numa compreensão automática. A metáfora não deve ser "estranha (pois seria de difícil compreensão), nem superficial (pois não produz nenhuma impressão)"(1998, 1412b30-32). Em outros termos, ela não deve envolver analogias demasiado distantes - difíceis para um público de ilustração modesta - nem inteiramente triviais e familiares. A essas últimas faltaria, por sua vez, uma qualidade essencial à boa metáfora: o prazer da atividade da descoberta. Nesse ponto, faz notar o filósofo, tudo se passa de modo similar ao caso do

\footnotetext{
${ }^{11}$ Aristóteles afirma em 1404a5 que o estilo "consiste num processo de expor e destina-se a um ouvinte".

${ }^{12}$ Comentando a passagem que viemos de mencionar, A. Laks faz um reparo acerca do tipo de conhecimento que a metáfora promove. Não se trata simplesmente da indicação do referente de um termo, pois nesse caso por que diria Aristóteles que os termos comuns, de nós conhecidos, não nos trazem ensinamento, como o faz a metáfora? Mas trata-se antes do conhecimento da "relation entre la chose et la manière de s'y référer" ou "d'une opération lexicale (et non d'une enquête sur la nature des choses)". Ele nos diz: "Le thème de la facilité cognitive permet de comprendre le rôle que le nom métaphorique est appelé à jouer en rhétorique. Il est essentiel de voir que, et pourquoi, la fonction référentielle des termes usuels, rappelée par la mineure ta; de; ojnovmata shmaivnei ti, n'est pas ici considerée comme porteuse d'une fonction cognitive, que seuls les noms métaphoriques se voient reconnaître. Quel est donc le "plus" cognitif que la métaphore ajoute à la monstration du référent? Il ne consiste nullement dans la connaissance d'une "chose", mais plutôt, et encore une fois au second degré, de la relation entre la chose et la manière de s'y référer." (1994, p.298).

${ }^{13}$ V. $1410 \mathrm{~b} 20$.

${ }^{14}$ V. 1410b19.
} 
entimema: quando este é superficial não se reserva um trabalho de investigação ao ouvinte, e se o priva, em conseqüência, da satisfação que resultaria dessa atividade. ${ }^{15}$

Podemos observar então que a metáfora, recurso estilístico maior do estilo retórico, age mediante a produção de um triplo prazer. Inicialmente, como vimos em 1404b9, o prazer da desfamiliarização: o que foge ao ordinário, também no domínio da expressão lingüística, é agradável. Em segundo lugar, a instrução propiciada pelo deslocamento metafórico porque é ela própria uma instrução tanto quanto porque não exige esforços do público proporciona igualmente satisfação, conforme 1410b11. E, finalmente, é prazerosa a própria sensação de atividade que acompanha a busca de resolução do enigma envolvido na metáfora ${ }^{16}$. Se as coisas se passassem no discurso retórico como no discurso da ciência, à exceção da demonstração tudo seria supérfluo, não se procurando nele, portanto, "desagradar ou agradar (mete lypein mete euphrainein)"(1998, 1404a4) Contudo, o discurso retórico não pode se limitar como o ensino à mera demonstração, o orador não pode falar a seu público enquanto professor de geometria. ${ }^{17}$ Precisamente em razão da deficiência do público, a dimensão demonstrativa do discurso deve estar acompanhada de uma outra, igualmente essencial: a dimensão de entretenimento, de prazer. Abrigada pelo estilo, esta terá por função auxiliar no trabalho de fazer com que o que se diz apareça ao público, lhe seja expressivo, isto é, ajudará a neutralizar as várias dificuldades do público. É por esse motivo que o estilo retórico procura por diferentes meios o prazer do público, ${ }^{18}$ como se fosse verdadeiro o princípio de que, com aqueles que apresentam dificuldade em aprender, a dimensão de prazer da aprendizagem constitui para o que ensina aliado precioso.

$\mathrm{O}$ ingrediente de prazer é precisamente o que faz da metáfora um recurso estilístico de sucesso (eudomikon) entre o público, assim como elegante e de bom gosto (asteion). $\mathrm{O}$ orador deve ter em vista o que faz sucesso e parece elegante ao ouvinte, justamente por coincidir com o que é no mais alto grau capaz de angariar sua adesão à opinião transmitida, isto é, com o que é mais persuasivo. Os recursos estilísticos desse tipo são, não por coincidência, os mais aptos a neutralizar suas dificuldades de compreensão, fixação da atenção e indisposição em relação ao discurso.

Vale lembrar, entretanto, que outros artifícios do estilo, além da metáfora, poderão produzir o efeito de desfamiliarização. No que tange ao ritmo por exemplo, o que mais convém ao discurso retórico não coincide com o da linguagem ordinária, o jambo, pois o estranhamento não se produziria, nem tampouco o da poesia, que elevaria o discurso fazendo-o parecer resultado de arte, tornando-o portanto, não-persuasivo. Deve-se mais uma vez encontrar a meia distância entre esses dois tipos de discurso. O ritmo mais conveniente será o pean (paian), que, por um lado, não sendo um ritmo exato, passará despercebido, e, por outro lado, constituindo-se numa espécie de ritmo evitará os efeitos de uma ausência rítmica, isto é, parecer desagradável e indiscernível. ${ }^{19}$

Um outro modo de obter o efeito de desfamiliarização na fala do orador será por meio de uma certa elevação que ela poderá incorporar, sem que se assemelhe nisso, porém, com a poesia. Note-se que Aristóteles afirma em 1404b4-5 que o estilo retórico "não deve ser rasteiro nem acima do seu valor, mas sim adequado. É verdade que o estilo poético não será porventura rasteiro, mas nem por isso é apropriado a um discurso em prosa." A necessidade de que o estilo retórico porte uma relativa solenidade é sugerida em 1408b34-36, acerca do ritmo, justamente enquanto meio de distinção em relação à linguagem ordinária: "o jambo, por seu turno, é a própria lingugem da maioria das pessoas (por isso, de entre todos os metros, é o jambo que ao falarmos mais utilizamos); no entanto, o discurso deve ser solene e capaz de emocionar. " É interessante notar que, embora o discurso retórico não possa ser tão solene quanto o poético, terá, a fim de se distinguir da linguagem ordinária, de comportar certa elevação. Há, com efeito, um limite inferior que não deve ser ultrapassado, ponto que, vale dizer, o estilo retórico partilha com o da poesia. ${ }^{20}$ Essa relativa elevação, ao mesmo tempo que afasta o discurso retórico da linguagem comum, o aproxima da poesia. $\mathrm{O}$ ouvinte deve assim ter a impressão de um discurso algo mais

\footnotetext{
${ }^{15}$ V. 1410b20-25. Em 1400b28-32 Aristóteles nos diz que uma das espécies de entimema da preferência do público é a que, sem ser trivial, lhe reserva um trabalho de descoberta, o que por si mesmo é prazeroso: "De todos os silogismos refutativos e demonstrativos, os de maior aplauso são aqueles em que, sem ser superficiais, se prevê desde o princípio a conclusão (porque os ouvintes sentem-se, ao mesmo tempo, mais satisfeitos, pelo fato de os terem pressentido), assim como aqueles que só são entendidos à medida que vão sendo enunciados".

${ }^{16}$ V. 1405b4-5.

${ }^{17}$ V. Ética a Nicômaco, 1094b26-27.

18 A preocupação com a dimensão de prazer do estilo na retórica está presente em vários dos capítulos III, 2-12. Aparece explicitamente nas seguintes passagens: 1409a34-b3, 1410a20-23, 1408b28-29, 1410b35, 1412a20-28.

19 V. 1409a6-8.

${ }^{20}$ V. Poética, $1458 \mathrm{a} 18$.
} 
grave e solene que o discurso ordinário, o que acarretaria os efeitos da desfamiliarização, quais sejam, prazer, captação da atenção e expressividade.

Há ainda uma série de formas de expressão que, afastando-se das formulações da linguagem comum, operam a desfamiliarização e são por essa razão consideradas elegantes (asteia) pelo público, isto é, têm a sua preferência. São elas, nos diz Aristóteles, as que conduzem a engano (proexapatan), enunciam o que não dizem (me ho phesi legein), ou ainda formulam o inesperado (to kaina legein). ${ }^{21}$ Tal ocorre nas sentenças (apophthegmata), nos enigmas (enigmena), nos chistes (skomata) que envolvem jogos de palavras, ou quando a mesma palavra é usada em acepções diferentes. Todas essas formas de expressão rompem com o esperado pelo ouvinte e precisamente por isso criam nele, diz o filósofo, uma convicção de verdade, ou seja, têm o poder de instruí-lo. ${ }^{22}$

Todos esses recursos de desfamiliarização só poderão contudo alcançar o efeito esperado se se fizerem claros para o ouvinte. Aristóteles insiste sobre esse ponto ao longo dos capítulos III,2-12 e faz da clareza a outra grande exigência a ser imposta ao estilo retórico, que é colocada nestes termos: "a virtude suprema da expressão enunciativa (lexis) é a clareza. Sinal disso é que se o discurso não comunicar algo com clareza, não perfará a sua função própria."(1998, 1404b2-6) Sendo a função própria da linguagem remeter adequadamente para aquilo que significa, a clareza será uma exigência imposta não apenas ao discurso retórico, mas a toda espécie de discurso. O próprio estilo da poesia deverá acomodar-se a essa exigência. Aristóteles parece, todavia, pensar que o refinamento do estilo poético-como, por exemplo, as metáforas distantes de Górgias ${ }^{23}$-, além de inadequado na retórica, por fazer o discurso parecer artificial e técnico, poderia roubar deste a clareza. A excessiva elaboração do estilo poderia no limite operar contra a exigência de clareza. Conforme assinala S. Halliwell, para o filósofo a falta de clareza não é tão cheia de implicações na poesia como na retórica. ${ }^{24}$ Pois, nesta última, o objetivo maior do orador é esclarecer o ouvinte acerca da investigação a que se procede, ${ }^{25}$ é propriamente instruí-lo sobre do caso em discussão, a fim de que melhor elabore seu julgamento. A dimensão de instrução (mathesis) dos componentes do estilo retórico é insistentemente apontada por Aristóteles.

Parece-nos, em conclusão, que todos os esforços de Aristóteles no estudo do estilo retórico no livro III vão no sentido de mostrar que a responsabilidade maior desse estilo é a de dar a ver, de tornar expressivo, de fazer acessível ao público da retórica - o da assembléia e do tribunal, dotados de pesadas responsabilidades cívicas, que são - aquilo que se diz. Isto é, vão no sentido de mostrar a relevância do estilo para o ultrapassamento das dificuldades que obstam o bom esclarecimento do ouvinte, a fim de que o exercício de julgamento possa se desdobrar em condições favoráveis à vitória da tese justa e verdadeira.

\section{BIBLIOGRAFIA}

ARISTÓTELES. Retórica. Traduzido por M. Alexandre Júnior, P. F. Alberto e A. N. Pena. Lisboa, Imprensa Nacional-Casa da Moeda, 1998.

. The "art" of rhetoric. Traduzido por H. Freese. Cambridge, Massachusetts, Harvard

University Press/London, William Heinemann, 1975. (1 $1^{a}$ edição 1926).

.On the soul. Traduzido por W. S. Hett. Cambridge, Massachusetts, Harvard University

Press/London, William Heinemann, 1986. (1ª edição 1936).

.The Nicomachean ethics. Traduzido por H. Rackham. Cambridge, Massachusetts, Harvard

University Press/London, William Heinemann, 1975. (1ª edição 1926).

\footnotetext{
${ }^{21}$ V. $1412 \mathrm{a} 18-25$.

${ }^{22}$ V. $1412 \mathrm{a} 18-\mathrm{b} 8$

${ }^{23}$ V. $1406 \mathrm{~b} 8-16$.

24 "To say that a 'foreign' term or a simile which are out of place in a forensic speech might be appropriate in epic is not to say that the style to which they generally belong is a clear style - only, perhaps, that in so far as the style falls short of complete clarity, this matters much less in, say, an epic poem than it would do in a court of law. In this sense the Rhetoric leaves open the possibility that the notion of clarity is one which is inversely proportional to stylistic artifice." (1993, p. 58).

${ }^{25}$ Quanto a ser uma investigação (skepsis) o julgamento que tem lugar na assembléia e tribunal onde atua o orador v. 1357 a24.
} 
On poetics. Traduzido por I. Bywater. Chicago/London/Toronto, Encyclopædia Britannica, 1952.

HALLIWELL, Stephen. Style and sense in Aristotle' rhetoric Book 3. In: Revue Internationale de Philosophie, Bruxelles, v. 47, n. 184, p. 50-69, 1/1993.

LABARRIERE, Jean-Louis. L'orateur politique face à ses contraintes. In: FURLEY, David \& NEHAMAS, Alexander (orgs). Aristotle's rhetoric, philosophical essays. Princeton, Princeton University Press, 1994.

LAKS, André. Substitution et connaissance: une interprétation unitaire (ou presque) de la théorie aristotélicienne de la métaphore. In: FURLEY, David \& NEHAMAS, Alexander (orgs). Aristotle's Rhetoric: philosophical essays. Princeton, Princeton University Press, 1994.

SENNETT, Richard. O Declínio do homem público, as tiranias da intimidade. Traduzido por Lygia Watanabe. São Paulo, Companhia das Letras, 1988. 